\title{
Dealing with healthcare waste... a waste of time?
}

SADJ November 2018, Vol. 73 No. 10 p635

Dr Brown was proud of his practice and never tired of showing patients around to view the latest equipment he had installed. No expense had been spared and he was in possession of a Cone Beam radiographic unit and the most advanced sterilization facilities. The dental chairs incorporated every advanced feature. He was particularly conscious of the special arrangements he had made for the storage and disposal of used hypodermic needles which, using artery forceps to avoid needle sticks, were carefully placed into a glass jar which was securely closed by a screw-on lid. The jar was labelled in red and when full was placed into the waste bins for collection by the municipal refuse organization.

Although extractions in his practice were infrequent, those that he had removed were also placed into the same glass jar for disposal.

Dr Brown may well have had the most up to date equipment and practised the most advanced Dentistry but of course... the practice was guilty of gross mishandling of waste. Booklet Number 12 of the HPCSA Guidelines dealing with Ethical issues, presents a Motivation for the Booklet: "The HPCSA views the proper disposal of healthcare waste by healthcare practitioners as an essential element of good professional practice. These Guidelines are issued to remind practitioners of their ethical and professional obligations to their patients and to the community."

The Council defines a wide range of waste as hazardous, listed below:

Infectious waste, pathological waste, including body fluids, secretions and surgical specimens, sharps, especially contaminated sharps, pharmaceutical waste, chemical waste, heavy metals, radioactive waste, genotoxic waste, cytotoxic agents, pressurised containers.

Should the waste fall into one of those categories, special arrangements must be made for handling the material.

The problems of unsafe handling of sharps may be relatively obvious... there will be a danger of needle stick injuries and the risk of the transmission of infectious agents. What may be the problems if healthcare waste is dumped into municipal landfill sites? Not only will there be potential physical injuries but also exposure to infection suffered by formal landfill workers and by informal scavengers of the rubbish. Contamination of groundwater could readily result in the spread of $E$ Coli. Even the burning of healthcare waste is not recommended as the environment is polluted, with the formation of dioxins. Incineration may overcome these dangers.
Good ethical practice demands that a set of guidelines for the management of healthcare waste should be respected and effected by every practitioner. The HPCSA emphasizes a number of requirements which are deemed essential to ensure effective and ethical management of healthcare waste.

Paramount amongst these is the dictate that every practice should utilise a healthcare waste disposal system that meets the requirements of the relevant South African National Standards code (Code of Practice of the South Africa Bureau of Standards on the Handling and Disposal of Waste Material within HealthCare Facilities SANS 10248 $12008)$.

Such a system should provide for the minimization of waste, for the segregation, packaging, labeling, storage and removal of the material under circumstances that do not pose a threat to human health or the environment. There are service providers handling healthcare waste disposal who will satisfy these requirements. An audit trail should be recorded to provide evidence of this arrangement.

All medical sharps, whether contaminated or not, are hazardous and should be disposed of in appropriate specific containers which cannot be punctured or broken, should be stable and resistant to impact. They must not be filled over capacity.

It is the responsibility of health care practitioners to ensure that, if necessary, they should keep up to date with the latest scientific knowledge on the safe management of healthcare waste by undergoing further training in waste management. Further, that should a practitioner become aware of evidence of unsafe disposal of waste by any person or institution, it is incumbent upon him/her to report that delinquency to both the HPCSA and to the Department of Health.

Failure to adhere to these guidelines will be considered to be unethical and unprofessional conduct on the part of the healthcare practitioners concerned.

The management of healthcare waste is a serious issue, unfortunately overlooked by Dr Brown.

\section{Reference}

Guidelines for the management of healthcare waste. Booklet 12: Guidelines for Good Practice in the Healthcare Professions. Health Professions Council of South Africa. 2016 